\title{
Genetic variability among different Italian populations of the aphid Myzus persicae
}

\author{
Criniti $^{1}$ Angela, Emanuele Mazzoni ${ }^{2}$, Nicola Pecchioni ${ }^{1}$, Domenico Rau ${ }^{3}$, Stefano \\ Cassanelli $^{1}$, Davide Bizzaro ${ }^{4}$ and Giancarlo Manicardi ${ }^{1 *}$ \\ ${ }^{1}$ Dipartimento di Scienze Agrarie Università di Modena e Reggio Emilia; ${ }^{2}$ Istituto di Entomologia e Patologia Veg- \\ etale, Università Cattolica Sacro Cuore di Piacenza; ${ }^{3}$ Dipartimento di Scienze degli Alimenti - DISA - Università \\ Politecnica delle Marche, Ancona. ${ }^{4}$ Istituto di Biologia e Genetica, Università Politecnica delle Marche, Ancona.
}

\begin{abstract}
Aphids life cycle includes cyclical or obligate parthenogenesis, therefore low genetic variation is expected in these insects. Genetic diversity in crop pest aphids such as Myzus persicae, is also influenced by the extensive use of insecticides which favoured the selection of few resistant strains. In the present work, $18 \mathrm{M}$. persicae populations collected in different Italian regions, were studied by RAPD-PCR (Random Amplified Polymorphic DNA) to assess genetic variability among populations. Twelve different random primers, selected out of 24 previously investigated, were employed for genomic DNA amplification. A total of 150 fragments from the aphid M. persicae populations, and 31 fragments in two outgroups were identified. An UPGMA cluster analysis based on NEI and LI's genetic distance revealed that the M. persicae populations could be divided into two groups: aphids from Central and Southern Italy were generally located in the same cluster, while aphids from Northern Italy were more often located in the other. The presence of a positive correlation between genetic and geographical distance suggests that at least a portion of the interpopulation polymorphism evidenced could be caused by restricted gene flow.
\end{abstract}

Key Words: Aphid, Genetic variability, Interpopulation polymorphism, Molecular markers, Myzus persicae, RAPD-PCR.

\section{INTRODUCTION}

A peculiar feature of aphids biology is their viviparous reproduction consisting in several generations of apomictic (asexual) parthenogenesis, followed by a single sexual generation at the end of each season (holocicly). Moreover, some species or populations within species have completely or partially abandoned any sexual stage and are obligately parthenogenetic (anholocicly) (for a review see HALES et al. 1997). Limited genetic variation is thus expected in aphid species as a consequence of their extensive use of apomictic parthenogenesis, especially in those consisting mainly or exclusively of anholocyclic clones. Since many aphid species are major plant pests, their genetic diversity is also lowered by the extensive use of insecticides. Among crop pest insects, the peach-potato aphid Myzus persicae is, without any doubts, one of the

\footnotetext{
* Corresponding author: Dipartimento di Scienze Agrarie, Università di Modena e Reggio Emilia, Viale Kennedy 17, 42100 Reggio Emilia, Italy. Phone: (+39) 522 522059; fax: (+39) 522522053 ,e-mail: manicardi.giancarlo@unimore.it
}

most representative species and one of the most serious pest on a wide range of crops. It is presumably of Asian origin like its primary host, the peach (Prunus persica), but it is globally distributed today (BLACKMAN \& EASTOP 2000). This very polyphagous species accepts secondary host plants from over 40 different botanic families, including many economically important crops in which it can cause direct damage and/or it can transmit more than 100 plant pathogenic viruses (BLACKMAN \& EASTOP 2000). M. persicae normally reproduce by cyclical parthenogenesis but this species also shows numerous and irreversible transitions from cyclical to obligate parthenogenesis.

Since the parthenogenetic eggs are produced by mitosis in which there is no recombination (BLACKMAN 1979), parthenogenetic generations are often regarded as clones in which only mutations could produce genetic variability. Moreover, recent anthropogenic selection, such as insecticide treatment, could further explain the low genetic variability observed at a large scale since pesticide resistance has often evolved from the recent appearance and spread of single (or a few) adaptive genes, which are selected for over large geo- 
graphical areas (Vorburger 2006). Studies addressing genetic diversity in aphid populations started with allozyme analysis which, as expected, revealed much less allozyme variation in aphids than in other invertebrate taxa (Томiuk \& WoHRMANN 1980). A novel range of molecular biology-based techniques are being widely used to study population genetics, which include mitochondrial DNA, RAPD-PCR (Random Amplified Polymorphic DNA) and microsatellites (SunNUCKs 2000). The use of short arbitrary oligonucleotides as primers for DNA amplification in PCR reactions (i.e., RAPD-PCR), demonstrated the potential of this approach to detect both interspecific (MARTINEZ Torres et al. 1997) and interpopulation (ZITOUDI et al. 2001) genetic variations among aphids. Reproducible RAPD banding pattern differences were also observed between winged, wingless and sexual (male or female) morphs of the same species (Lushar et al. 1997). The disadvantages of RAPDs as a consequence of dominance and low reproducibility are counterbalanced by the essentially infinite number of genomic markers generated together with the possibility to elute and sequence a peculiar RAPD band to produce a codominant marker (Lushai et al. 1997; BASHASAB et al. 2006). In this study, RAPD-PCR was chosen as a convenient molecular method for assessing the genetic variability among $18 \mathrm{M}$. persicae populations collected in different Italian peach-growing regions.

\section{MATERIAL AND METHODS}

M. persicae collections were made on peach orchards from 18 sites in different Italian regions (Fig. 1, Table 1). In order to reduce the variables which could influence genetic variability, we focused our attention on populations all collected from the same host (Prunus persicae) during spring time. This sampling strategy eliminated the genetic variability caused by different host adap-

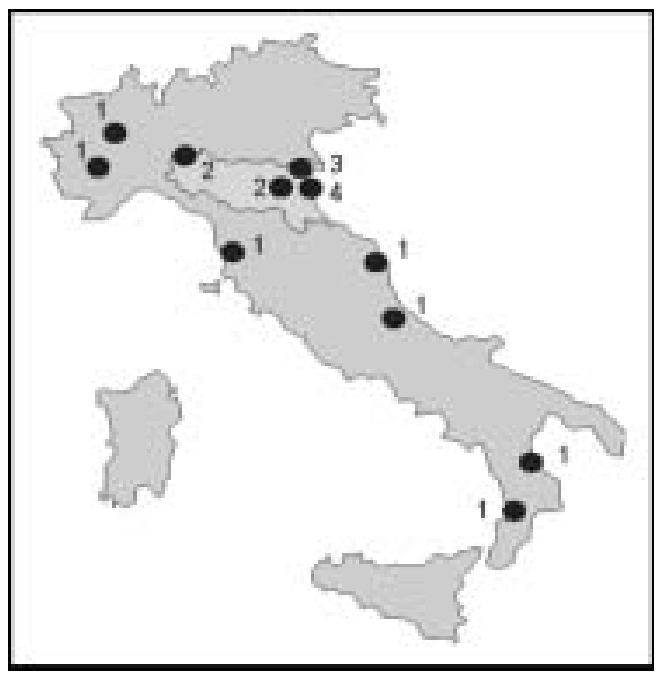

Fig. 1 - Geographic distribution of the sampling sites and numbers of collected samples per site. The Region Emilia-Romagna is indicated in lighter grey.

Table 1 - Population codes, geographic origin, number of positive ' 1 ' bands per population, and latitude/longitude coordinates of the sampling sites

\begin{tabular}{|c|c|c|c|}
\hline Population & Region - Town and (province) & $\begin{array}{l}\text { Number of positive ' } 1 \text { ' } \\
\text { bands per population }\end{array}$ & Lat/Long \\
\hline $\mathrm{Mp}-1$ & Toscana - Pisa (PI) & 47 & $10^{\circ} 24^{\prime} 53^{\prime \prime} / 43^{\circ} 42^{\prime} 42^{\prime \prime}$ \\
\hline $\mathrm{Mp}-3$ & Emilia Romagna - Imola (BO) & 51 & $11^{\circ} 43^{\prime} 0 ” / 44^{\circ} 21^{\prime} 11^{\prime \prime}$ \\
\hline $\mathrm{Mp}-12 \mathrm{H}$ & Emilia Romagna - Argenta (FE) & 45 & $11^{\circ} 50^{\prime} 11^{\prime \prime} / 44^{\circ} 36^{\prime} 47^{\prime \prime}$ \\
\hline Mp-17 & Emilia Romagna - Piacenza (PC) & 56 & $9^{\circ} 42^{\prime} 0 ” / 45^{\circ} 2^{\prime} 51^{\prime \prime}$ \\
\hline Mp-18 & Emilia Romagna - Brisighella (RA) & 55 & $11^{\circ} 46^{\prime} 33^{\prime \prime} / 44^{\circ} 13^{\prime} 21^{\prime \prime}$ \\
\hline Mp-19 & Emilia Romagna - Piacenza (PC) & 44 & $9^{\circ} 42^{\prime} 0 ” / 45^{\circ} 2^{\prime} 51^{\prime \prime}$ \\
\hline Mp-20 & Emilia Romagna - Brisighella (RA) & 51 & $11^{\circ} 46^{\prime} 33^{\prime \prime} / 44^{\circ} 13^{\prime} 21^{\prime \prime}$ \\
\hline Mp-24 & Emilia Romagna - Imola (BO) & 51 & $11^{\circ} 43^{\prime} 0 " \prime / 44^{\circ} 21^{\prime} 11^{\prime \prime}$ \\
\hline Mp-28 & Emilia Romagna - Faenza (RA) & 48 & $11^{\circ} 52^{\prime} 34^{\prime \prime} / 44^{\circ} 17^{\prime} 32^{\prime \prime}$ \\
\hline $\mathrm{Mp}-34$ & Calabria - Lamezia Terme (CZ) & 40 & $38^{\circ} 54^{\prime} 28^{\prime \prime} / 16^{\circ} 14^{\prime} 30^{\prime \prime}$ \\
\hline Mp-36 & Emilia Romagna - Porotto (FE) & 46 & $44^{\circ} 50^{\prime} 0 ” / 11^{\circ} 37^{\prime} 0 ”$ \\
\hline $\mathrm{Mp}-37$ & Emilia Romagna - Argenta (FE) & 48 & $11^{\circ} 50^{\prime} 11^{\prime \prime} / 44^{\circ} 36^{\prime} 47^{\prime \prime}$ \\
\hline $\mathrm{Mp}-38$ & Emilia Romagna - Ravenna (RA) & 48 & $12^{\circ} 12^{\prime} 0 ”$ / $44^{\circ} 25^{\prime} 0^{\prime \prime}$ \\
\hline Mp-46 & Piemonte - Torino (TO) & 52 & $7^{\circ} 40^{\prime} 34^{\prime \prime} / 45^{\circ} 4^{\prime} 41^{\prime \prime}$ \\
\hline Mp-58 & Marche - Ascoli Piceno (AP) & 51 & $13^{\circ} 37^{\prime} 52^{\prime \prime} / 42^{\circ} 50^{\prime} 53^{\prime \prime}$ \\
\hline Mp-64 & Abruzzo - Paglieta $(\mathrm{CH})$ & 52 & $14^{\circ} 29^{\prime} 53^{\prime \prime} / 42^{\circ} 9^{\prime} 50^{\prime \prime}$ \\
\hline $\mathrm{Mp}-70$ & Calabria - Castrovillari (CS) & 51 & $16^{\circ} 12^{\prime} 47^{\prime \prime} / 39^{\circ} 49^{\prime} 16^{\prime \prime}$ \\
\hline Mp-TO1 & Piemonte - Torino (TO) & 62 & $7^{\circ} 40^{\prime} 34^{\prime \prime} / 45^{\circ}$ 4' 41"' \\
\hline $\mathrm{Mp}-1$ & Toscana - Pisa (PI) & 47 & $10^{\circ} 24^{\prime} 53^{\prime \prime} / 43^{\circ} 42^{\prime} 42^{\prime \prime}$ \\
\hline
\end{tabular}


tation which, although $M$. persicae is one of the most polyphagous aphids known, has been repeatedly demonstrated (ZiTOudi et al. 2001; VoRBURGER et al. 2003). Moreover, limiting the collection time to spring, we intended to reduce the effect of different reproductive strategies, since we assumed that practically all populations analysed were holociclics.

Samples were taken from one leaf per plant, infested with nymphs, apterae and alatae and were maintained on pea-seedlings (Pisum sativum) under constant conditions: $21 \pm 1^{\circ} \mathrm{C}$, $16 \mathrm{~h}$ light: $8 \mathrm{~h}$ dark. For use as outgroups in RAPD analysis Aphis pomi DeGeer and Achyrthosiphon pisum Harris were also collected. Our outgroup taxa are all members of the Family Aphididae, subfamily Aphidinae. All the populations were analysed using the RAPD-PCR method. Genomic DNA was extracted from 10-15 living adults per population according to CASSANELli et al. (2005).

Twelve decamer primers (Operon Technologies) were used in the study (OPA-01, OPA-02, OPA-05, OPA-11, OPB-08, OPB-10, OPB-11, OPE-19, OPQ-05, OPQ-15, OPW-19, OPZ-08) selected from 24 previously tested. Polymerase chain reactions were performed by using the same thermalcycler (Hybaid) in $25 \mu \mathrm{l}$ reaction mixture containing $300 \mathrm{ng}$ of template DNA, $1.5 \mathrm{U}$ of Taq polymerase (Polymed), $0.2 \mathrm{mM}$ dNTPs, $20 \mathrm{ng}$ of each primer, $2.5 \mathrm{mM} \mathrm{MgCl}$, and $1 \mathrm{X}$ reaction buffer supplied by the enzyme manufacturer. Amplification conditions involved one preliminary denaturation at $94^{\circ} \mathrm{C}$ for $2 \mathrm{~min}$, a total of 35 cycles of a strand denaturation at $94^{\circ} \mathrm{C}$ for $1 \mathrm{~min}$, annealing at $35^{\circ} \mathrm{C}$ for $1 \mathrm{~min}$, and primer extension at 72 for $1 \mathrm{~min}$, followed by final extension period of 10 min at $72^{\circ} \mathrm{C}$. Then the amplified products were screened in $1.5 \%$ agarose gel containing $0,5 \mu \mathrm{g}$ $\mathrm{ml}^{-1}$ Ethidium Bromide in 1X TBE buffer. Each gel was run at $60 \mathrm{~V}$ for $2 \mathrm{~h} 30^{\prime}$, DNA bands were visualized under UV light (Fig. 2) and were scored for their presence or absence. The molecular weight of each band was estimated by comparison with a co-migrating $100 \mathrm{bp}$ ladder (O'Range Ruler 100 bp ladder, MBI Fermentas). To avoid problems related to variation in the number and intensity of amplification products, band mobility comparisons were made only within gel and based on the same PCR reaction. Each PCR reaction was replicated twice to check for reproducibility of the RAPD patterns produced. For detecting genetic similarity among populations, a data matrix for each primer was produced, each individual being represented as a vector of 1 and 0 , for the presence or absence of a fragment.

A binary matrix was obtained and was transformed into a similarity matrix using the similarity coefficient of NEI \& LI (1979). From this matrix a dendrogram was obtained by cluster analysis following the unweighted pair-group method of analysis (UPGMA)(SNEATH \& SOKAL 1973), using TreeCon Software version 1.3 (VAn De Peer \& De Watcher 1994).

The bootstrap support of the nodes (1000 replicates) was calculated for the RAPD tree. Differentiation between clusters was estimated calculating and testing (with 10000 permutations) $\mathrm{F}_{\mathrm{ST}}$ statistics (WRIGHT 1951) by using the TFPGA software (Miller 1997).

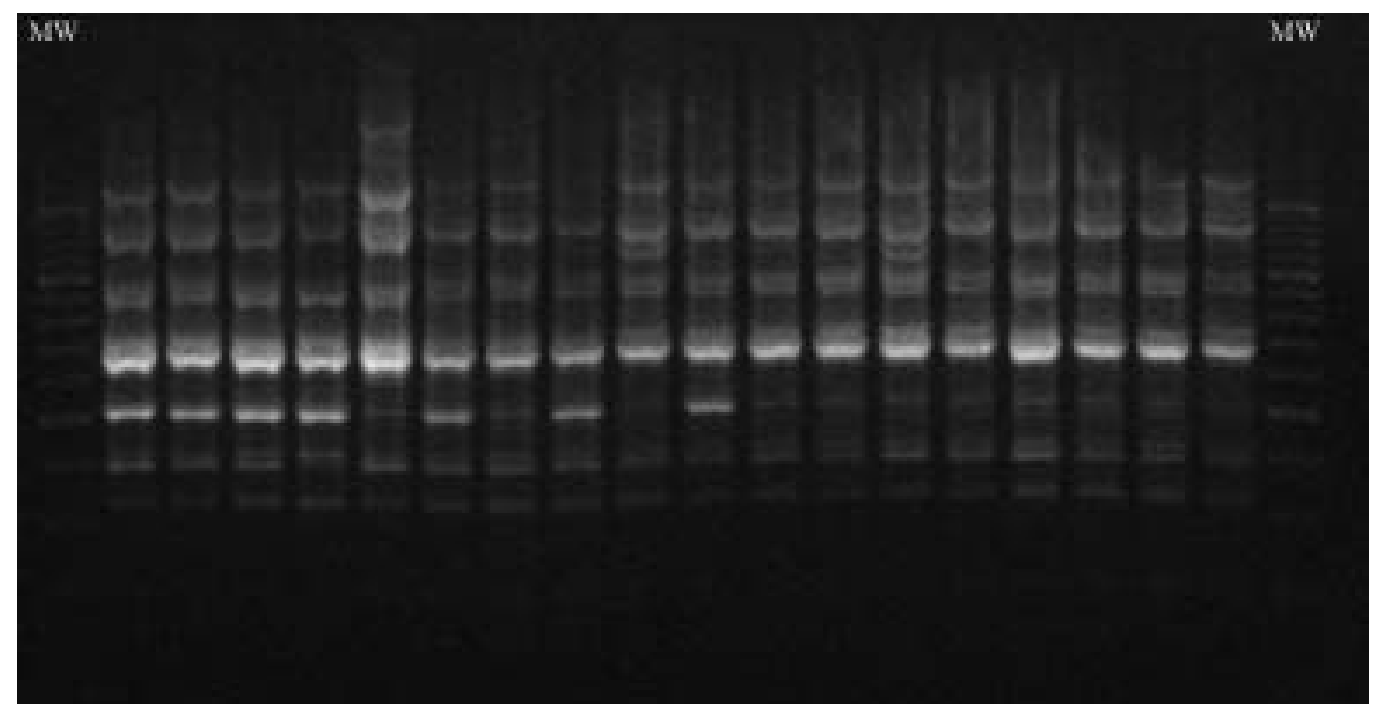

Fig. 2 - Amplified sequences obtained with the primer OPQ5 and separated in 1.5\% agarose gel. 
To test if differences among populations were influenced by geographic distance, we correlated the genetic distance between pairs of populations against the $\log _{10}$ transformed geographical (linear) distance $(\mathrm{Km})$ between pairs. The significance of the correlation $(\mathrm{P})$ was tested using the Mantel test (1967) with 10000 random permutations and using the AIS software (MILLER 2005).

Distances among collecting sites were estimated from the latitude and the longitude. Moreover, for this analysis when dominant markers are available, AIS uses a simple genetic distance that is the proportion of mismatched loci between any pairs of individuals $i$ and $j$ in a data set.

\section{RESULTS}

Random amplified polymorphic DNA (RAPD) analyses applied to 18 population of $M$. persicae collected in different Italian regions using 12 decamer primers produced a number of fragments varying from 7 to 14 per primer, ranging in size from 250 to $1500 \mathrm{bp}$. All primers used allowed the detection of a total of 150 reproducible and well-resolved bands for the $18 \mathrm{M}$. persicae populations (Table 1 ) and 31 exclusive markers in the two outgroups analysed, for a total of 181 markers analysed. Similarity indices calculated following NEI \& LI (1979) obtained by a data matrix considering all the RAPD markers (data not shown), showed that the highest genetic similarity was registered between the Mp-46 and Mp-58 populations $(0.775)$, whereas the lowest between Mp-34 and Mp-TO1 (0.133). Distance matrix used to construct a phenogram with 1000 bootstrap replicates produced a dendrogram showing that the separation of the $M$. persicae complex as a whole from the two outgroups, was strongly supported with $96 \%$ bootstrap value (Fig. 3). Moreover, within the $M$. persicae populations, aphids from Northern Italy were generally differentiated from those collected in Central and Southern Italy since they were preferentially located in different clusters The two clusters were supported with $61 \%$ and $66 \%$ bootstrap values, which suggests they were not somewhat arbitrary. The upper cluster, including most Northern populations, showed in general a lower genetic diversity within the strains. Among them, the MpTO1 population collected near Torino, in the North-West of Italy (see Fig. 1), resulted differentiated from the others with $100 \%$ bootstrap confidence. On the contrary, the other cluster, which included all Central and Southern Italy populations analysed (with the only exception of Mp-58, from Ascoli Piceno, which grouped with those from Northern Italy) generally showed a higher divergence among the

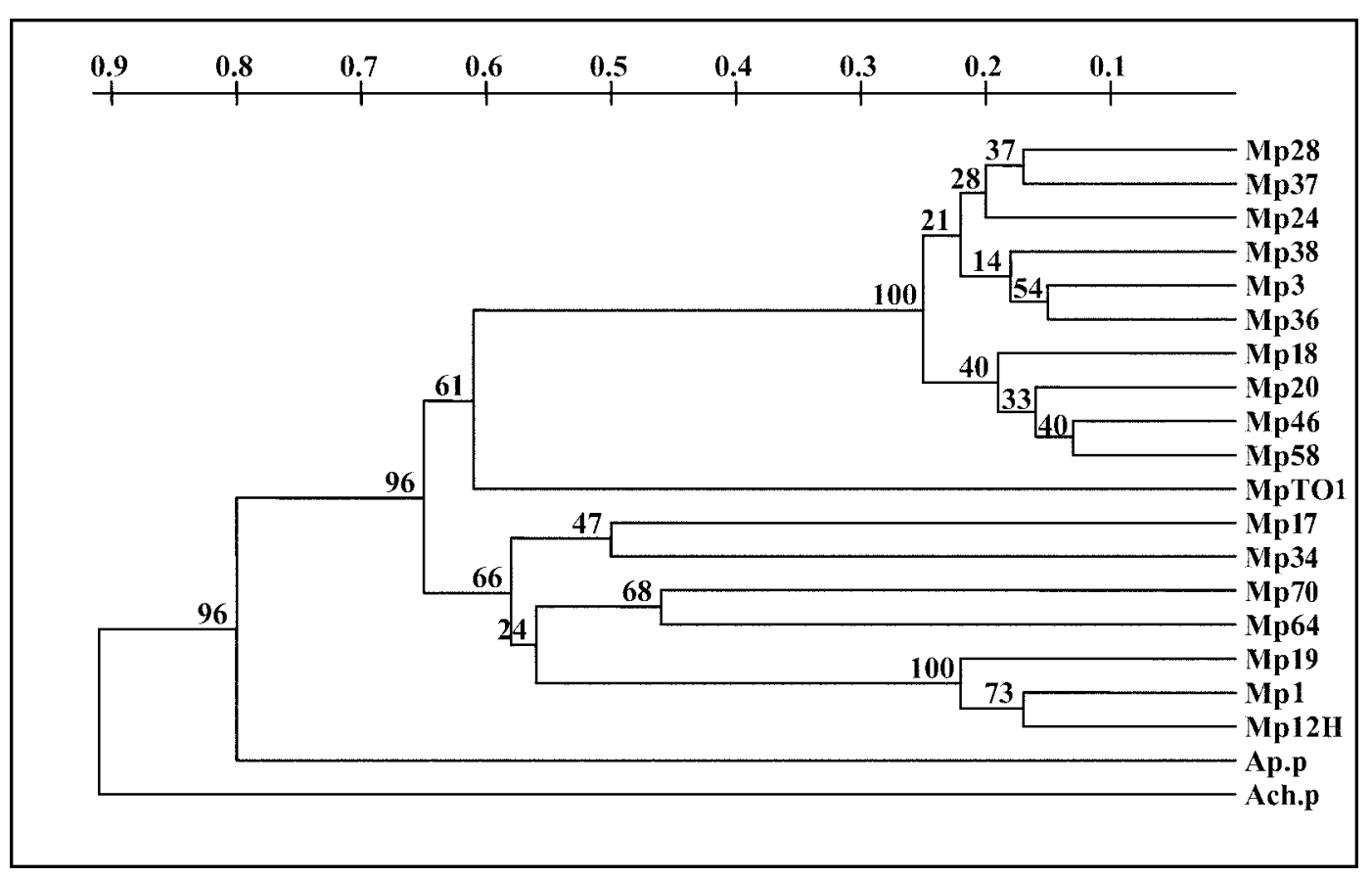

Fig. 3 - UPGMA dendrogram generated from the similarity distance matrix. Bootstrap confidence levels for 1000 pseudo-replicated data matrices are indicated. The two outgroups are indicated as following: Ap.p = Aphis pomi, Ach.p = Acirthosiphon pisum 
included populations. Genetic differentiation between the two clusters was strong and significant $\left(\mathrm{F}_{\mathrm{ST}}=0.399 \mathrm{P}<0.01\right)$.

When the entire dataset was considered, the correlation between genetic and geographic distances among population-bulks resulted highly significant and positive $(r=0.429, P=0.0046)$ (Figure 4A). Moreover, the correlation was also significant when only the Emilia Romagna region was considered $(r=0.568, P=0.0228)$ (Figure 4B).

\section{DISCUSSION}

Reproductive strategies, together with genetic drift and natural selection are generally invoked to account for low genetic variability among aphid species. In the peach-potato aphid, Myzus persicae genetic diversity is also lowered by the large use of the insecticides which, starting from 1950s favoured the selection of resistant strains (ZAMOUM et al. 2005). However, both cytogenetics (SPENCE \& BLACKMAN 2000) and molecular studies (for a review see WiLson et al. 2003) show that an appreciable level of genetic variation in $M$. persicae does exist. For example, biochemical studies carried out in Myzus persicae populations, show that allozyme loci were found to be excessively monomorphic thus suggesting that they could be under selection pressure (DelmotTe et al. 2002). By using hypervariable microsatellite markers or ITS fingerprints, several studies have shown that asexually reproducing populations of $M$. persicae sampled on herbaceous plants displayed a low genotyping variability, both within and among populations at a regional scale (FENTON et al.1998; GUILlEMAUd et al. 2003; Vorburger et al. 2003). On the contrary, molecular characterization of the Tunisian M. persicae clones using microsatellite markers made possible the detection of an unexpected high number of genotypes (DJILANi KHOUADJA et al. 2003).

In order to increase the knowledge above the extent of genetic variation for this important crop pest aphid, we have applied the RAPD-PCR technique to $18 \mathrm{M}$. persicae populations collected in different Italian areas, with a particular emphasis regarding the Emilia and Romagna Region, which represents one of the largest peach growing areas in Europe.

The RAPD-PCR technique, based on the amplification of genomic DNA with single primers of arbitrary nucleotide sequence, has provided an advantageous molecular technique able to detect genetic markers both in plants and animals.

Some RAPD analyses had been previously carried out also within $M$. persicae populations, but the conclusion differed. For example, AL-ABoodi and FFrench-Constant (1995) detected no variation when comparing 32 clones from Canada and two from England besides CLEMENTs et al. (2000) reported that RAPD polymorphisms didn't separate populations on the basis either of host-plant association or of geographic origin. However, CENIs et al. (1993) were able to distinguish a German clone from five identical Spanish clones and MARTINEZ-Torres et al. (1997) discovered that almost every clone of $M$. persicae from a Spanish region differed. Moreover, genetic variation associated with host-plant and life cycle but not with

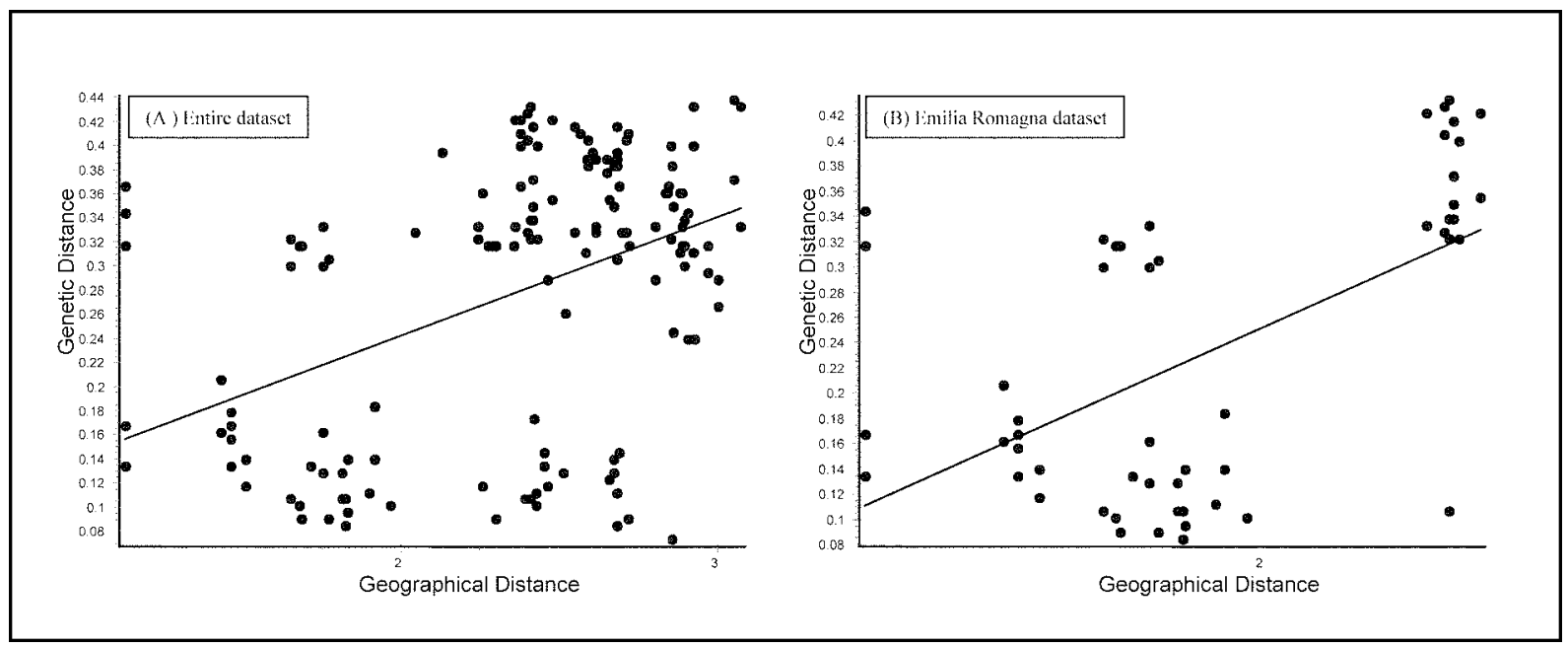

Fig. 4 - Relationships between genetic divergence and geographic distance among the $M$. persicae Italian populations when the entire dataset $(\mathrm{A})$ or only the Emilia Romagna dataset $(\mathrm{B})$ are considered. 
geographic distance was observed in Greek populations (ZiToudi et al. 2001)

In the present study, the 150 reproducible and well-resolved RAPD-PCR bands obtained by us put in evidence a substantial amount of variation in RAPD profiles among the 18 populations of $M$. persicae examined.

The level of interpopulation genetic similarity was found to vary from 0.133 to 0.775 and, owing to the cluster analysis, it was associated with geographic origins. In fact, $M$. persicae populations collected from Central and Southern Italy were generally located in the same cluster while those from Northern Italy, with few exception, were located in a different one. Moreover, within the two clusters there was a different level of variability since populations collected from Central and Southern Italy presented an higher genetic divergence than those collected in Northern Italy. A possible reason for this last result could be that $M$. persicae from Northern Italy were mostly collected in Emilia-Romagna, which is the main region in Italy in the peach production.

The observed significant correlation between genetic and geographic distance is consistent with other studies on this species (LOXDALE 1990; Martinez-Torres et al. 1997; Wilson et al. 2002; Guillemaud et al. 2003) but Zitoudi et al. (2001) failed to show an association between genetic divergence and geographic distance when examining 96 asexual lineages of $M$. persicae collected in different Greek regions. The presence of a significant population differentiation with increasing geographical distance could be explained by suggesting that, contrary to what previously supposed (VAN EMDEM et al. 1969; HALES et al. 1997) long distance migration is not so common in $M$. persicae. The presence of a restricted gene flow among sites is also supported by the observation that the correlation remains significant also when the analysis is restricted only to the Emilia Romagna region (i.e. not only at the country scale but also at a smaller geographical scale). Alternatively it could be hypothesized that, even in presence of long distance migration, the success rate of migration may be low (LOXDALE and Lushai 1999; Guillemaud et al. 2003). Moreover, the relationship between genetic differentiation and geographical distance found in M. persicae by us and other Authors (LOXDALE et al. 1993; SunNuCKs et al. 1997; GuILlEMAUd et al. 2003) resulted higher than that observed in other aphid species (Delmotte et al. 2002; DolatTi et al. 2005) thus suggesting that, as already discussed (LoxDALE et al. 1993), migration capacity results largely variable among different aphid species.

Since our collection strategy was aimed to avoid effects on genetic variability due to host adaptation and reproductive strategy (see Material and methods) among other possible reasons able to explain the observed genetic difference between $M$. persicae populations we could suggest climatic (temperature) variations in the Italian environments, quali/quantitative differences regarding natural enemies (parasitoids and predators) but also differences in pest management strategies.

Temperature has long been identified as one of the most important environmental variables in aphid ecology (Hales et al. 1997) and genetic variation among clones associated with their different temperature tolerance has been detected in M. persicae (VORBURGER et al. 2003).

On the other hand, it is possible that populations collected in different regions are under different selection factors depending from the species and the natural enemies present in the collecting field.

Last but not least also the different phytosanitary history can account for the observed results as, in many cases, the populations were collected in insecticides sprayed orchards. Further analyses, carried out utilizing increasing number of populations and different molecular markers could give additional important contributions to the stimulating study of genetic variability in $M$. persicae.

Acknowledgements - This work was supported by a grant from Italian Ministero della Ricerca Scientifica e Tecnologica (MURST): Cofin 2005.

\section{REFERENCES}

Al-Aboodi A. and Ffrench-Constant R.H., $1995-$ RAPD PCR confirms absence of genetic variation between insecticide resistant variants of green peach aphid Myzus persicae (Homoptera: Aphididae). Gt Lakes Entomol, 28: 127-133.

Bashasab F., Vijaykumar R., Kambapally K.B., PaTIL B.V. and KuruvinASHETTI M.S., 2006 - DNAbased marker systems and their utility in entomology. Entomol. Fennica, 17: 21-33.

BLACKMAN R.L., 1979 - Stability and variation in aphid clonal lineages. Biol. J. Linn. Soc., 11: 259-277.

BLACKMAN R.L. and EASTOP V.F., 2000 - Aphids on the World's Crops: An Identification and Information Guide. $2^{\text {nd }}$ ed John Widely \& Sons Ltd. 
Cassanelli S., Cerchiari B., Giannini S., Bizzaro D., Mazzoni E. and Manicardi G.C., 2005 - Use of the RFLP-PCR diagnostic test for characterizing $M A C E$ and KDR insecticide resistance in the peach potato aphid Myzus persicae. Pest Management Science, 61: 91-96.

Cenis J.L., Perez P. and Fereres A., 1993 - Identification of aphid (Homoptera: Aphodidae) species and clones by random amplified polymorphic DNA. Ann. Entomol. Soc. Am., 86: 545-550.

Clements K.M., Sorenson C.E., Wiegmann B.M., Neese P.A. and Roe R.M., 2000 - Genetical, biochemical, and behavioral uniformity among populations of Myzus nicotianae and M. persicae. Entomologia Experimentalis et Applicata, 95:269-281.

Delmotte F., Leterme N., Gauthier J.P., Rispe C. AND Simon J.C., 2002 - Genetic architecture of sexual and asexual populations of the aphid Rhopalosiphum padi based on allonzyme and microsatellite markers. Mol. Ecology, 11: 711-725.

Djilani Khouadja.F., Rouze-Jouan J., Simon J.C., Leterme N., Bou Hachem S., Marrackhi M. AND FaKHFAKH H., 2003 - Molecular typing of tunisian clones of Myzus persicae (Hemiptera Pphididae) using microsatellite markers. Entomol. Croat., 1-2: 51-62.

Dolatti L., Ghareyazie B., Moharrimipour S. and Noori-Dalor M.R., 2005 - Evidence for regional diversity and host adaptation in Iranian populations of the Russian wheat aphid. Entomologia experimemtalis et applicata, 114: 171-180.

Fenton B., Woodford J.A.T. and Malloch G., 1998 - Analysis of clonal diversity of the peach-potato aphid, Myzus persicae (Sulzer), in scotland, UK and evidence for the existence of a predominant clone. Mol Ecol, 7: 1475-1487.

Guillemaud T., Mieuzet L. and Simon J.C., 2003 Spatial ad temporal genetic variability in French populations of the peach-potato aphid, Myzus persicae. Heredity, 91: 143-152.

Hales D.F., Tomiuk J., Wohrmann K. and Sunnucks P., 1997 - Evolutionary and genetic aspects of aphid biology: a review. Eur. J. Entomol., 94: 1-55.

LoXdalE H.D., 1990 - Estimating levels of gene flow between natural populations of cereal aphids (Homoptera, Aphididaea). Bull. Entomol. Res., 80: 331-338.

Loxdale H.D., Hardie J., Halbert S., Footit R., Kidd N.A.C. and CARTER C.I., 1993 - The relative importance of short-and long-range movement of flying aphids. Biological Review, 68: 291-311.

Loxdale H.D. and Lushai G., 1999 - Slaves of the environment: the movement of herbivorous insects in relation to their ecology and genotype. Philos. Trans. R. Soc. Lond. B, 354: 1479-1495.

Lushai G., Loxdale H.D., Brookes C.P., Von Mende N., Harrington R. and Hardie J., 1997 Genotypic variation among different phenotypes within aphid clones. Proc. R. Soc. London B, 264: 725-730.
Mantel N., 1967 - The detection of disease clustering and a generalized regression approach. Cancer Res, 27: 209-20.

Martinez-Torres D., Carriò R., Latorre A., Simon J.C., Hermoso A. and Moya A., 1997 - Assessing the nucleotide diversita of three aphid species by RAPD. Journal of evolutionary biology, 10: 459477.

Miller M.P., 1997 - TFPGA. Tools for population Genetic Analysis. Version 1.3. Northern Arizona.

Miller M.P., 2005 - Alleles in Space: computer software for the joint analysis of inter-individuals spatial and genetic information. In press on Journal of Heredity.

NeI M. and LI W., 1979 - Mathematical model for studying genetic variation in terms of restriction endonuclease. Proc Natl Acad Sci USA, 76: 5269. 5273.

Sneath P.H.A. and Sokal R.R., 1973 - Numerical taxonomy. San Francisco, W.H. Freeman \& Co.

SPENCE J.M. and Blackman R.L., 2000 - Inheritance and meiotic behaviour of a de novo chromosome fusion in the aphid Myzus persicae (Sulzer). Chromosoma, 109: 490-497.

Sunnucks P., De Barro P.J., Lushai G., MacleanN. AND Hales D.F., 1997 - Genetic structure of an aphid studied using microsatellites: cyclic parthenogenesis, differentiated lineages and host specialization. Molecular Ecology, 6: 1059-1073.

SunNuCKs P., 2000 - Efficient genetic markers for population biology. Trends in Ecology and Evolution, 15: 199-203.

Tomiuk J. and Wohrmann K., 1980 - Enzyme variability in populations of aphids. Theor Appl Gen, 57: 125-127.

VAn De Peer Y. and De Watcher R.D., 1994 TREECON for Windows: a software package for the construction and drawing of evolutionary trees for the Microsoft Windows environment. Comput Applic Biosci, 10: 569-570.

VAn Emdem H.F., EAstop V.F. and Way M.J., 1969 - The ecology of Myzus persicae. Ann Rev Entomol, 14: 197-270.

Vorburger C., LANCAster M., and Sunnucks P., 2003 - Enviromentality related patterns of reproductive modes in the aphid Myzus persicae and the predominance of two 'superclones' in Victoria, Australia. Mol. Ecology, 12: 3493-3504.

Vorburger C., 2006 - Temporal dynamics of genotypic divesity reveal strong clonal selection in the aphid Myzus persicae. J. Evol. Biol., 19: 97-107.

Wilson A.C.C., Sunnucks P., Blackman R.L., and Hales D.F., 2002 - Microsatellite variation in cyclically parthenogenetic populations of Myzus persicae in south-eastern Australia. Heredity, 88: 258266.

Wilson A.C.C., Sunnucks P. and Hales D.F., 2003 Hereditable genetic variation and potential for adaptive evolution in asexual aphids (Apbidoidea). Biol. J. Linnean Soc., 79: 115-135. 
Wright S., 1951 - The genetical structure of populations. Ann. Eugen, 15: 323-354.

Zamoum T., Simon J.C., Crochard D., Ballanger Y., Lapchin L., Vanleberge-Masutti F., and Guillemaud T., 2005 - Does insecticide resistance alone account for the low genetic variability of asexually reproducing populations of the peach- potato aphid Myzus persicae? Heredity, 94: 630639.

Zitoudi K., Margaritopoulos J.T., Mamuris Z. and Tsitsipis J.A., 2001 - Genetic variation in Myzus persicae populations associated with host-plant and life cycle category. Entom. Experim. et Applicata, 99: 303-311. 